\title{
Graphene Oxide based Label Free Ultrasensitive Immunosensor for Lung Cancer Biomarker, hTERT
}

Meenakshi Choudhary ${ }^{1,2}$, Veeresh Kumar ${ }^{3,4}$, Anu Singh ${ }^{1}$, Manoj P. Singh ${ }^{1}$, Satbir Kaur ${ }^{2}$, G.B. Reddy ${ }^{4}$, Renu Pasricha $^{3}$, Surinder P. Singh ${ }^{3}$ and Kavita Arora ${ }^{1 *}$

${ }^{1}$ Advanced Instrumentation Research Facility (AIRF), Jawaharlal Nehru University (JNU), New Mehrauli Road, New Delhi, India ${ }^{2}$ Department of Human Genetics, Punjabi University, Patiala, Punjab, India

${ }^{3}$ CSIR-National Physical Laboratory (NPL), Dr. K. S. Krishnan Marg, New Delhi, India

${ }^{4}$ Department of Physics, Indian Institute of Technology, Hauz Khas, New Delhi, India

\begin{abstract}
We report the fabrication of ultrasensitive Graphene Oxide (GO) based electrochemical immunosensor to detect human telomerase reverse transcriptase (hTERT), a lung cancer biomarker. The immuno-electrode-has been fabricated by covalent immobilization of rabbit anti-hTERT antibodies (Ab) onto GO films on ITO coated glass. The Fourier Transform Infrared (FTIR) spectroscopic studies confirms the presence of diverse organic functional groups $(-\mathrm{COOH},-\mathrm{CHO},-\mathrm{OH})$ of $\mathrm{GO}$, and the binding (anti-hTERT) onto GO/ITO electrode. Interestingly, Scanning Electron Micrographs (SEM) also reveals clear visual surface modification of the GO film by anti-hTERT antibodies and hTERT antigen (Ag). The electrochemical Differential Pulse Voltammetry (DPV) results show that the GO based immunosensor exhibits specificity and low detection upto $10 \mathrm{ag} \mathrm{mL}^{-1}\left(10 \times 10^{-18} \mathrm{~g} \mathrm{~mL}^{-1}\right)$ in wide detection range $(10 \mathrm{ag}$ $\mathrm{mL}^{-1}-50 \mathrm{ng} \mathrm{mL}^{-1}$ ) for hTERT. The immunosensor showed ability to detect hTERT in spiked sputum samples upto 100 $\mathrm{fg} \mathrm{mL}^{-1}$ in dynamic detection range of $100 \mathrm{fg} \mathrm{mL}^{-1}-10 \mathrm{ng} \mathrm{mL}^{-1}$. The enhanced performance of Ab/GO/ITO is attributed to fast electron transfer and efficient loading of $A b$ on large surface area provided by $G O$ network. The low level detection of hTERT warrants the realization of point-of-care device for early detection of lung/oral cancer through oral fluids.
\end{abstract}

Keywords: Lung cancer; hTERT; Electrochemical immunosensor; Graphene oxide

Abbreviations: GO: Graphene Oxide; ITO: Indium Tin Oxide; Ab: Antibody; hTERT: Human Telomerase Reverse Transcriptase; BSA: Bovine Serum Albumin; AFM: Atomic Force Microscopy; SEM: Scanning Electron Microscopy; XRD: X-Ray Diffraction; CV: Cyclic Voltammetry; DPV: Differential Pulse Voltammetry; TEM: Transmission Electron Microscopy; FTIR: Fourier Transform Infrared Spectroscopy; EDC: 1-Ethyl-3-(3-Dimethylaminopropyl) Carbodiimide; NHS: N-Hydroxysulfosuccinimide; AFP: Alpha Fetoprotein; AuNP: Gold Nanoparticles; GDCS: Graphene Doped Chitosan; PTH: Polymerized Thionine; GCE: Glassy Carbon Electrode; Fc: Ferrocene; Gr: Graphene; TiO2: Titanium Dioxide; GOx: Glucose Oxidase; PBSE: 1-Pyrene-Butanoic Acid Succinimidyl Ester; PSA: Prostate Specifc Antigen; Chi: Chitosan; Py: Pyrrole; $\mathrm{M}^{2+}: \mathrm{Metal}^{2+}$; ANTA: N-AlphaBis (Carboxymethyl)-L-Lysine; Si: Silicon; NSE: Neuron Specific Enolase; FET: Field Effect Transistors; SWNT: Single Walled Carbon Nanotubes; GO: Graphene Oxide; Diuron: 3-(3:4-Dichlorophenyl)-1: 1-Dimethylurea; AP: Alkaline Phosphatase; HRP: Horseradish Peroxidase; SWV: Square Wave Voltammetry; fG: Functionalized Graphene; SPE: Screen Printed Electrode; ITO: Indium Tin Oxide; SPCS: Screen-Printed Carbon Strips; ABA-g-SPCE: P-Aminobenzoic Acid Grafted Screen Printed Carbon Electrodes; CYFRA-21: Cytokeratin 19 fragment; hnRNP A2-B1: Heterogenous Nuclear Ribonucleoprotein A2-B1; MAGE-11: Melanoma Associated Antigen-11

\section{Significance of Research}

Unavailability of apposite diagnostic test capable of monitoring early stage progression/relapse of lung cancer is related to its high mortality rate wordwide. We report for the first time detection of lung cancer biomarker hTERT (human telomerase reverse transcriptase), using anti-hTERT for fabrication of graphene oxide (a low cost unique multifunctional material) based immunosensor in spiked sputum samples in the dynamic detection range of $100 \mathrm{fg} \mathrm{mL}^{-1}-10 \mathrm{ng} \mathrm{mL}^{-1}$ in $30 \mathrm{~s}$ exposure time. The easy fabrication of above said electrochemical immunosensor warrants the development of low cost and non invasive diagnostics (first and second stages) for lung cancer.

\section{Introduction}

Cancer is a major health problem worldwide, where poor prognosis of the disease significantly contributes to its monstrous nature [1]. Among various type of cancers, lung cancer is the most prevalent in males worldwide and remain a leading cause of cancer related deaths $(\sim 18.2 \%)$. In year $2008 ; 16,07,000$ cases of lung cancer with $13,75,000$ deaths around the globe and 58,000 lung cancer cases with 51,000 deaths in India [2]. One of the major causes of high mortality rates in lung cancer is unavailability of appropriate diagnostic test capable of monitoring early stage progression/relapse. About $70 \%$ lung cancer cases are diagnosed in advanced stage resulting in poor survival chances. Contemporary methods for lung cancer detection are Computed Tomography (CT) scan, Positron-Emission Tomography (PET) Scan, thoracoscopy, Magnetic Resonance Imaging (MRI), fluorescence bronchoscopy, sputum cytology, mediastinoscopy, needle biopsy (fine needle aspiration), pulmonary function tests, blood tests, immunological methods. However, all these tests identify the cancer at advanced stage and are time consuming, expensive, and require trained

*Corresponding author: Kavita Arora, Advanced Instrumentation Research Facility (AIRF), Jawaharlal Nehru University (JNU), New Mehrauli Road, New Delhi, India, E-mail: kavitaarora@jnu.ac.in

Surinder P. Singh, CSIR-National Physical Laboratory (NPL), Dr. K. S. Krishnan Marg, New Delhi, Delhi, India, E-mail: singhsp@mail.nplindia.org

Received July 30, 2013; Accepted September 06, 2013; Published September 13,2013

Citation: Choudhary M, Kumar V, Singh A, Singh MP, Kaur S, et al. (2013) Graphene Oxide based Label Free Ultrasensitive Immunosensor for Lung Cancer Biomarker, hTERT. J Biosens Bioelectron 4: 143. doi: 10.4172/2155-6210.1000143

Copyright: (c) 2013 Choudhary M, et al. This is an open-access article distributed under the terms of the Creative Commons Attribution License, which permits unrestricted use, distribution, and reproduction in any medium, provided the original author and source are credited. 
manpower [3,4]. In recent years, advances in molecular characterization and identification of newer cancer biomarkers in biological fluids led to immense possibilities of developing the specific assays to detect and monitor the cancer progression/relapse at early stage [5]. Biomarkers like CYFRA-21, Carcinoembryonic antigen, hnRNP A2-B1, MAGE-11, hTERT, D-dimers are reported to have elevated level in biological fluids of lung cancer patients [6]. Among these, elevated expression of human telomerase reverse transcriptase (hTERT) in sputum/saliva is regarded as a hallmark of tumorigenesis [7]. hTERT is the catalytic subunit of telomerase on chromosome $5 \mathrm{p} 15.33$, and is a rate-limiting determinant of the enzymatic activity [8]. Telomerase activity in human cancer is associated with cell immortalization and acquisition of malignancy with majority of normal tissues [9]. Fernandez-Marcelo et al. [10] have shown that $77.8 \%$ cases exhibits telomerase activity during $1^{\text {st }}$ stage of lung cancer. The free circulating DNA of human telomerase reverse transcriptase gene (hTERT) has also been found in blood plasma at first and second stages of lung cancer, enabling early stage cancer detection by DNA based tests [11].

Altered protein/biomarker levels are routinely measured using Enzyme-Linked Immunosorbent Assay (ELISA), electrophoretic immunoassay, Radioimmunoassay (RIA) and mass spectrometry-based proteomics [12]. These methods are sensitive, accurate and precise, but required expensive instruments, materials, trained manpower and longer time for detection are major bottlenecks [13]. Immunosensors, a class of biosensors, presents more attractive option because of design simplicity and ease of operation to develop point of care diagnostics. The most critical step for fabrication of immunosensor involves selection of analyte, biological recognition element (i.e. antibodies), and a suitable immobilization matrix (electrode material) for desired transducer system. A variety of immobilization matrices (nanomaterials, polymers, conducting polymers, carbon nanotubes, self-assembled monolayers etc.) and immobilization methods have been used to fabricate electrochemical, optical, mass based transducer systems for fabrication of biosensors [14]. Inert metals, such as platinum or gold and carbon based materials, have been commonly used as electrochemical transducers for biosensors [15]. The low cost carbon paste is regularly used as the electrode material because of simple construction, low background current and ability for surface regeneration. However, the difficulties in reproducing the composition of the paste and leaching of bio-molecule from electrode surface leading to short life time of electrode are the major drawbacks. The genesis of nanomaterials and nanotechnology have made possible to develop highly sensitive and miniaturized biosensors. Carbon nanomaterials (nanoporous carbon, fullerenes, carbon nanotubes, carbon nanofibers) have been used in development of biosensors with enhanced electrochemical properties. Most of carbon based materials considered to be biocompatible, facilitate easy biomolecule immobilization; exhibit reproducible electrochemical behavior, along with extraordinary physico-chemical properties.

Graphene, layer of carbon atoms arranged in a honeycombed network is viewed as a true planar aromatic macromolecule, and a basic building block of other carbon allotropes [16]. Graphene exhibits unusual structural characteristics, electronic flexibility, high planar surface $\left(2630 \mathrm{~m}^{2} / \mathrm{g}\right)$, and ballistic conduction of charge carriers $[17,18]$. As a result of the unique physico-chemical properties, dense cloud of charge carriers confined in atomic thickness; large chemically modifiable surface area, graphene and graphene-based nano-materials have attracted strong interest in bio-electronic devices [19,20].

Graphene oxide (GO), a chemical derivative of graphene, is considered as a promising material for biosensors due to excellent electrochemical properties, biocompatibility, high defect density and the presence of pendant organic functional groups $(-\mathrm{OH},-\mathrm{COOH},-\mathrm{CHO})$ [21]. GO can be electrostatically suspended in water due to the presence of carboxylic (-COOH) groups [22]. The $-\mathrm{COOH}$ groups allows easy attachment of various biomolecules, such as protein, enzyme and nucleic acids onto the GO sheets that warrants its use as electrode in the development of immunosensors. Various immunosensors based on varied matrices have been compared on the basis of their performance and are summarized in Table 1.

Taking into account the early stage expression of hTERT in oral fluids and synergetic thrust from multi-functional GO, we report the

\begin{tabular}{|c|c|c|c|c|c|c|c|c|}
\hline S. No & $\begin{array}{l}\text { Immobilization } \\
\text { matrix }\end{array}$ & Analyte & Label & $\begin{array}{l}\text { Detection } \\
\text { technique }\end{array}$ & $\begin{array}{l}\text { Detection } \\
\text { range }\end{array}$ & Detection limit & $\begin{array}{l}\text { Exposure } \\
\text { time }\end{array}$ & Ref. \\
\hline 1 & Anti-NSE/ SWNT/ GCE & NSE & AP & DPV & $0.033 \mathrm{ng} \mathrm{mL}^{-1}-2 \mu \mathrm{g} \mathrm{mL}^{-1}$ & $0.033 \mathrm{ng} \mathrm{mL}^{-1}$ & $60 \mathrm{~min}$ & [38] \\
\hline 2 & Anti CA15-3/TH-NPG-Gr/GCE & CA 15-3 & HRP & DPV & $5 \times 10^{-6}-40 \mathrm{UmL}^{-1}$ & $5 \times 10^{-6} \mathrm{U} \mathrm{mL}^{-1}$ & $30 \mathrm{~min}$ & [39] \\
\hline 3 & Anti-estradiol- Biotin/Strept-ABA-g-SPCE & Estradiol & HRP & Amperome try & $0.77 \mathrm{pg} \mathrm{mL}^{-1}-250 \mathrm{pg} \mathrm{mL}^{-1}$ & $0.77 \mathrm{pg} \mathrm{mL}^{-1}$ & $45 \mathrm{~min}$ & [40] \\
\hline 4 & $\begin{array}{l}\text { Anti-GH/ } \\
\text { disposable SPCS }\end{array}$ & $\begin{array}{l}\text { growth } \\
\text { hormone }\end{array}$ & $\begin{array}{l}\text { Lable } \\
\text { free }\end{array}$ & DPV & $25 \mathrm{pg} \mathrm{mL}^{-1}-200 \mathrm{pg} \mathrm{mL}^{-1}$ & $25 \mathrm{pg} \mathrm{mL}^{-1}$ & $30 \mathrm{~min}$ & [41] \\
\hline 5 & Anti CEA/APTES/ Si-FET & CEA & $\begin{array}{l}\text { Label } \\
\text { free }\end{array}$ & $\begin{array}{l}\text { AC lock-in } \\
\text { technique }\end{array}$ & $0.2 \mathrm{ng} \mathrm{mL}^{-1}-114 \mathrm{ng} \mathrm{mL}^{-1}$ & $0.2 \mathrm{ng} \mathrm{mL}^{-1}$ & $90 \mathrm{~min}$ & [42] \\
\hline 6 & $\begin{array}{l}\text { Anti HIgG/Gr } \\
\text { nanosheets- AuNP/GCE }\end{array}$ & HIgG & HRP & DPV & $0.05 \mathrm{ng} \mathrm{mL}^{-1}-200 \mathrm{ngmL}^{-1}$ & $0.05 \mathrm{ng} \mathrm{mL}^{-1}$ & $50 \mathrm{~min}$ & [43] \\
\hline 7 & AntiAFP/AuNP/G DCS/PTH/GCE & AFP & HRP & DPV & $0.7 \mathrm{ng} \mathrm{mL}^{-1}-10 \mathrm{ng} \mathrm{mL}^{-1}$ & $0.7 \mathrm{ng} \mathrm{mL}^{-1}$ & $25 \mathrm{~min}$ & {$[44]$} \\
\hline 8 & $\begin{array}{l}\text { Anti-CEA/Au-G/ } \\
\text { Chi-Fc/nano- } \mathrm{TiO}_{2} / \mathrm{GCE}\end{array}$ & CEA & $\begin{array}{l}\text { Label } \\
\text { free }\end{array}$ & $\mathrm{CV}$ & 3.4 $\mathrm{pg} \mathrm{mL}^{-1}-80 \mathrm{ng} \mathrm{mL}^{-1}$ & $3.4 \mathrm{pg} \mathrm{mL}^{-1}$ & $10 \mathrm{~min}$ & {$[45]$} \\
\hline 9 & $\begin{array}{l}\text { anti-D dimer/ poly } \\
\left(\text { py-pyANTA/M }{ }^{2+}\right) / A u\end{array}$ & D-dimer & $\begin{array}{l}\text { Label } \\
\text { free }\end{array}$ & DPV & $100 \mathrm{pg} \mathrm{mL}^{-1}-500 \mathrm{ng} \mathrm{mL}^{-1}$ & $100 \mathrm{pg} \mathrm{mL}^{-1}$ & $30 \mathrm{~min}$ & {$[46]$} \\
\hline 10 & $\begin{array}{l}\text { GOx/Gr/AuNPs/C } \\
\text { hi/ Gold electrode }\end{array}$ & Glucose & $\begin{array}{l}\text { Label } \\
\text { free }\end{array}$ & $\mathrm{CV}$ & $180 \mu \mathrm{M}-14 \mathrm{mM}$ & $180 \mu \mathrm{M}$ & - & {$[47]$} \\
\hline 11 & GOx/Gr-Chi/GCE & Glucose & $\begin{array}{l}\text { Label } \\
\text { free }\end{array}$ & $\mathrm{CV}$ & $0.02 \mathrm{mM}-12 \mathrm{mM}$ & $0.02 \mathrm{mM}$ & - & [48] \\
\hline 12 & $\begin{array}{l}\text { Anti-PSA/PBSE/ } \\
\text { Gr/polycarbonate surface }\end{array}$ & PSA & $\begin{array}{l}\text { Label } \\
\text { free }\end{array}$ & $\begin{array}{l}\text { multimeter } \\
\text { resistance test }\end{array}$ & $0.08 \mathrm{ng} \mathrm{mL}^{-1}-100 \mathrm{ng} \mathrm{mL}^{-1}$ & $0.08 \mathrm{ng} \mathrm{mL}^{-1}$ & - & [49] \\
\hline 13 & Anti-diuron/fG-GO/SPE & diuron & AP & SWV & $0.01 \mathrm{pg} \mathrm{mL}^{-1}-1000 \mathrm{ng} \mathrm{mL}^{-1}$ & $0.01 \mathrm{pg} \mathrm{mL}^{-1}$ & $20 \mathrm{~min}$ & [37] \\
\hline 14 & $\begin{array}{l}\text { Anti- } \\
\text { hTERT/GO/ITO }\end{array}$ & hTERT & $\begin{array}{l}\text { Label } \\
\text { free }\end{array}$ & DPV & $10 \mathrm{ag} \mathrm{mL}^{-1}-50 \mathrm{ng} \mathrm{mL}^{-1}-$ & $10 \mathrm{ag} \mathrm{mL}^{-1}$ & $30 \mathrm{~s}$ & $\begin{array}{l}\text { present } \\
\text { study }\end{array}$ \\
\hline
\end{tabular}

Table 1: Response characteristics of various immunosensors reported in literature. 
fabrication, characterization, optimization and application of antihTERT antibodies functionalized graphene oxide based electrochemical immunosensor for detection of lung cancer biomarker hTERT. The efficient and easy detection of hTERT from oral fluid and/or serum may bring a paradigm shift in prognosis and early stage detection of lung cancer.

\section{Experimental Section}

\section{Materials and reagents}

Graphite powder $(99.9 \%, 325$ mesh, Alfa aesar), Sulfuric acid $\left(\mathrm{H}_{2} \mathrm{SO}_{4}\right)$, Potassium permanganate $\left(\mathrm{KMnO}_{3}\right)$, Hydrogen peroxide $\left(\mathrm{H}_{2} \mathrm{O}_{2}\right)$, Sodium Nitrate $\left(\mathrm{NaNO}_{3}\right)$, 1-Ethyl-3-(3-dimethylaminopropyl) carbodiimide (EDC), N-hydroxysulfosuccinimide (NHS), Potassium ferricyanide $\left(\mathrm{K}_{3} \mathrm{Fe}(\mathrm{CN})_{6}\right)$, Potassium chloride $(\mathrm{KCl})$, Potassium phosphate monobasic $\left(\mathrm{KH}_{2} \mathrm{PO}_{4}\right)$, Potassium phosphate dibasic $\left(\mathrm{K}_{2} \mathrm{HPO}_{4}\right)$, Sodium chloride $(\mathrm{NaCl})$, Ethanolamine and Indium Tin Oxide (ITO) glass substrates were purchased from Sigma-Aldrich. Antigen hTERT and polyclonal anti-hTERT antibodies generated in rabbit were purchased from Bioss, USA. All the reagents/buffers have been prepared/diluted in sterile pyrogen free water from Nirlife Healthcare, Nirma Ltd. India.

\section{Synthesis of Graphene oxide}

GO was prepared by modified hummer's method [23]. In this process, $1 \mathrm{~g}$ of graphite powder and $1 \mathrm{~g}$ sodium nitrate $\left(\mathrm{NaNO}_{3}\right)$ were dissolved in $46 \mathrm{ml}$ of $\mathrm{H}_{2} \mathrm{SO}_{4}$ in an ice bath with continuous stirring. Thereafter, $6 \mathrm{~g}$ of $\mathrm{KMnO}_{4}$ flakes were slowly added to the above mixture under stirring, until this solution becomes dark green. This solution was then transferred to $35 \pm 5^{\circ} \mathrm{C}$ water bath and kept on vigorous stirring for one hour, to make a thick past. Further, $96 \mathrm{ml}$ of millipore water was added, and the solution was stirred for $30 \mathrm{~min}$ at $90 \pm 5^{\circ} \mathrm{C}$. To this solution, $200 \mathrm{ml}$ of water was added followed by the slow addition of 6 $\mathrm{mL}$ of $\mathrm{H}_{2} \mathrm{O}_{2}(30 \%)$, turning the color of the solution from dark brown to yellow. The warm solution was then filtered and washed with 200 $\mathrm{mL}$ of water. The filter cake were then dispersed in water by mechanical agitation and centrifuged for 3-5 times at low (2000 rpm) and high (8000 rpm) speed for 2 and $15 \mathrm{~min}$, respectively, and repeated until the supernatant attains neutral $\mathrm{pH}$. The final sediment was re-dispersed in water with sonication using ultrasonic cleaner, giving a solution of exfoliated GO.

\section{Preparation and characterization of GO/ITO electrode and Ab/GO/ITO Immunoelectrode}

Scheme 1 shows preparation of Ab/GO/ITO immunoelectrode. $25 \mu \mathrm{L} \mathrm{GO}\left(1 \mathrm{mg} \mathrm{mL}^{-1}\right)$, prepared by modified hummer's method was deposited onto ITO coated glass $(0.6 \times 0.8 \mathrm{~cm})$ via spin coating method. The GO/ITO electrode was exposed to $1: 1$ mixture of $\operatorname{EDC}(0.5 \mathrm{M})$ and NHS $(0.1 \mathrm{M})$ for $15 \mathrm{~min}$ to activate the terminal carboxyl group on GO surface for immobilization of anti-hTERT (Ab). $25 \mu \mathrm{l}$ of anti-hTERT antibodies $\left(2 \mu \mathrm{g} \mathrm{ml}^{-1}\right)$ was spread over the activated surface for $2 \mathrm{~h}$ and unbound antibodies were removed by rinsing the electrode with $10 \mathrm{mM}$ PBS. Remaining active sites were blocked using ethanolamine ( $0.96 \mathrm{M}$ for $5 \mathrm{~min}$ ) to avoid non specific binding. GO/ITO electrode and $\mathrm{Ab} / \mathrm{GO} / \mathrm{ITO}$ immuno-electrodes were characterized using Cyclic Voltammetry (CV), Differential Pulse Voltammetry (DPV), X-Ray Diffraction (XRD), Scanning Electron Microscopy (SEM), Fluorescent Transmission Infrared (FT-IR) spectroscopy, Transmission Electron Microscopy (TEM), Atomic Force Microscopy (AFM), etc.

\section{Response studies of $\mathrm{Ab} / \mathrm{GO} / \mathrm{ITO}$ immunoelectrode}

$\mathrm{Ab} / \mathrm{GO} / \mathrm{ITO}$ immuno electrodes were used to study the response

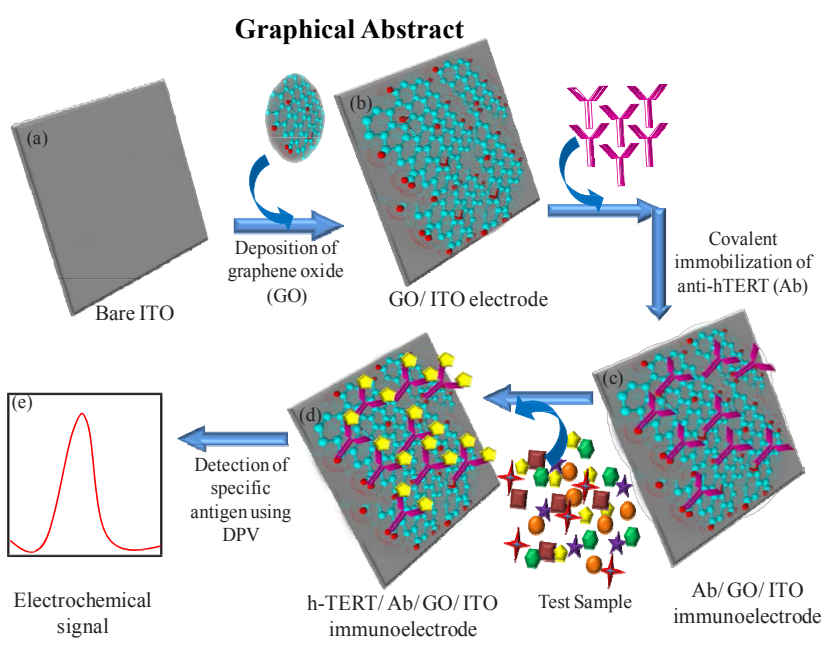

Scheme 1: Fabrication of GO based electrochemical immunosensor.

behavior for various concentrations of hTERT $\left(10 \mathrm{ag} \mathrm{mL}^{-1}-50 \mathrm{ng} \mathrm{mL}^{-1}\right)$ and hTERT spiked sputum samples (100 $\mathrm{fg} \mathrm{mL}^{-1}-10 \mathrm{ng} \mathrm{mL}^{-1}$ ) in $0.05 \mathrm{mM}$ Zobell's solution prepared with $5 \mathrm{mM}$ PBS in total volume $3 \mathrm{ml}$, using $\mathrm{DPV}$. The Ab/GO/ITO immuno-electrodes were exposed to various concentrations of hTERT with constant volume of $20 \mu \mathrm{l}$ for $30 \mathrm{~s}$ and washed with PBS before performing DPV electrochemical analysis.

\section{Instrumentation}

XRD spectra was obtained on BRUKER D8 Advance X-Ray Diffractometer using $\mathrm{Cu}$ Ka radiation $(\lambda=1.541 \AA)$. A Raman spectrum was taken on Varian FT Raman. AFM studies of GO were carried on by using AFM-Multimode-V, Veeco in tapping mode. High-Resolution Transmission Electron Microscopy (HR-TEM) images were monitored on a Tecnai G2 F30 S-Twin HRTEM, using an accelerating voltage of 200 $\mathrm{kV}$. The specimens were prepared on a carbon film coated copper grid (400 mesh), and then dried under room temperature. Electrochemical experiments were performed with an Autolab instrument PGSTAT302N (Eco Chemie B.V., Netherlands) by using a conventional threeelectrode system. GO coated ITO $(0.6 \times 0.8 \mathrm{~cm})$ electrode served as a working electrode, a platinum wire $(1.0 \mathrm{~mm}$ diameter $)$ as a counter electrode, and an $\mathrm{Ag} / \mathrm{AgCl}$ electrode $(3.0 \mathrm{~mm}$ diameter) with saturated $\mathrm{KCl}$ solution as a reference electrode. Cyclic Voltammetry $(\mathrm{CV})$ and Differential Pulse Voltammetry (DPV) measurements were carried out in $3 \mathrm{mM}$ Zobell's solution $\left(3 \mathrm{mM} \mathrm{K}_{3} \mathrm{Fe}(\mathrm{CN})_{6}\right.$ and $\left.0.1 \mathrm{M} \mathrm{KCl}\right)$ and $0.05 \mathrm{mM}$ Zobell's solution prepared in $5 \mathrm{mM}$ phosphate buffer saline (PBS, pH 7.4), respectively, at $25^{\circ} \mathrm{C}$ with $3 \mathrm{ml}$ working volume. Fourier Transform Infrared (FT-IR) spectra were carried out using a Nicolet 5700 FTIR spectrometer in the frequency range of $400-3800 \mathrm{~cm}^{1}$. Scanninng electron micrographs of modified electrodes were obtained using Zeiss EVO MF10 Scanning electron microscope. Thickness of GO film was obtained using Dektak-150 thickness profiler (Veeco Pvt Ltd.).

\section{Results and Discussion}

Scheme 1a-1e describes diagrammatic representation of fabrication of immunosensor for detection of hTERT, a lung cancer biomarker. Pre cleaned bare ITO (Scheme 1a) was used to deposit thin film $(\sim 15 \mathrm{~nm}$, Scheme $1 b$ ) of GO using simple spin coating method. Then, anti-hTERT (Ab) was covalently immobilized onto GO/ITO surface through EDC- 
NHS binding chemistry to fabricate the Ab/GO/ITO immunoelectrode, as shown in Scheme 1c. On exposure of prepared immunosensor with test sample antibody-antigen complex formed (Scheme 1d) that results in generation of electrochemical signal (Scheme 1e). The designed immunoelectrode was characterized at each stage of its development using XRD, Raman, AFM, FTIR, CV, SEM and HRTEM.

\section{Characterization of as synthesized Graphene oxide (GO)}

Figure 1A shows XRD spectra of as acquired graphite (curve 1) and GO (curve2), recorded using $\mathrm{Cu}$ Ka radiation $(\lambda=1.541 \AA$ ) on BRUKER D8 Advance X-Ray Diffractometer (Figure 1).

Strong diffraction peaks observed at $2 \theta$ value of $26.5^{\circ}$ for graphite and at $2 \theta$ value of $10.5^{\circ}$ for GO powder are ascribed to the (002) planes of graphitic structure. The inter-planer spacing d002 of GO and graphite was calculated to be $8.421 \AA$ and $3.36 \AA$, respectively, which are comparable to the reported results. The increased interlayer spacing for GO compared to graphite is attributed to the presence of various oxide/ epoxide groups and intercalated $\mathrm{H}_{2} \mathrm{O}$ molecules.

Further, the high value of $I_{D} / I_{G}(1.44)$ from Raman studies reinforce the formation of oxidized sheets of graphene, i.e. GO, as shown in Figure 1B. Figure 2A shows Atomic Force Microscope (AFM) image of
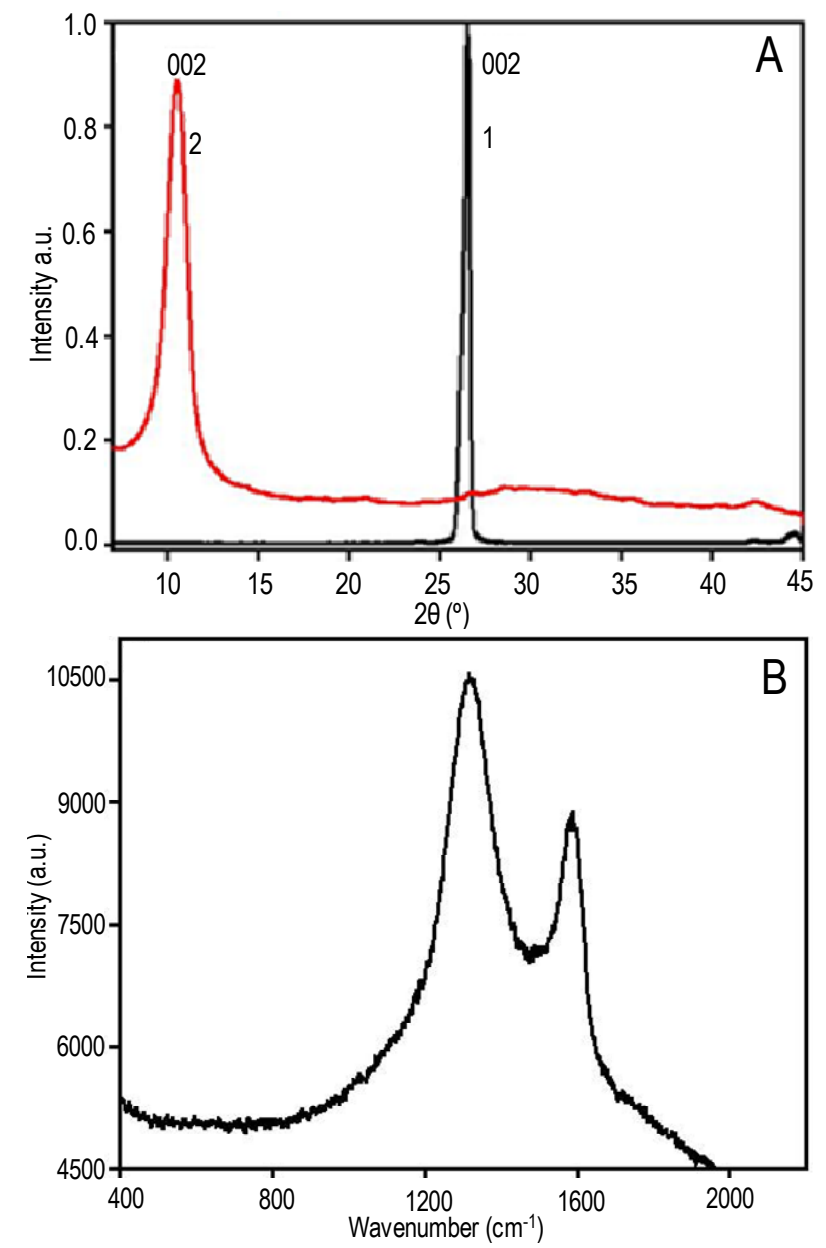

Figure 1: (A) XRD spectra of graphite (curve 1) and GO (curve 2); (B) Raman spectra of as synthesized GO.


Figure 2: (A) AFM images of the spin coated GO sheets; (B) TEM micrograph showing the spread out GO sheets; (C) HRTEM image showing the lattice image of single GO sheet; (D) IFFT reconstructed image clearly depicting the atomic resolution image of $\mathrm{GO}$, inset shows the SAED pattern from the multilayer region.

GO film on silicon wafer, in tapping mode. It can be seen that GO nanosheets with lateral dimensions of $\sim 2500 \mathrm{~nm}$ with few smaller sheets of $\sim 200 \mathrm{~nm}$ are well distributed onto silicon surface. Height profile analysis elucidates that the thickness of single GO sheet is approximately 0.87 $\mathrm{nm}$. Although, it is very difficult to achieve $100 \%$ single layer graphene using wet chemical methods, we have achieved sufficiently good distribution of GO nano-sheets by controlling synthesis conditions. It is, therefore, introspected that uniform distribution of nano-sheets contributes towards higher surface area allowing higher loading of biomolecules that will result in improved sensitivity of designed immunoelectrode. Figure $2 \mathrm{~B}$ shows the TEM micrographs of the chemically synthesized large area GO sheets with multi-layered folded areas. At low magnification, the presence of wrinkles and folds are prevalent that can also be considered as multilayered regions of GO sheet, otherwise, the areas showing the single unfolded sheet are highly transparent. Figure $2 \mathrm{C}$ shows the lattice plane of the single layer of GO with interplanar distance of $0.44 \mathrm{~nm}(4.40 \AA)$, which is more than $0.33 \mathrm{~nm}(3.30 \AA)$ interplanar distance of graphene, which is credited to the defects present in GO. Figure 2D shows inverse FFT (Fast Fourier Transform) reconstructed image of the lattice images shown in Figure 2C. This image clearly depicts the hexagonal unit cell of the graphitic structure, marked with the outline. Figure 2D shows the Selected Area Diffraction (SAED) pattern from the multi/double sheet region with a superposition of hexagonal patterns rotated by few degrees shows a ring pattern. This angle corresponds to a mis-orientation between multilayered GO sheets; an effect also observed recently in few-layer graphene samples [24]. The diffraction spots match the hexagonal lattice of graphitic structure. The d-spacing given by SAED pattern is $4.3 \AA$. We found the variation in the ' $\mathrm{d}$ ' value calculated from XRD and SAED pattern. It can be explained from the fact that the spacing between the layers decreases due to evaporation of $\mathrm{H}_{2} \mathrm{O}$ molecules when electron beam is focused onto the sample under vacuum. The lack of any diffraction spots other than those corresponding to the graphite structure shows that oxygen-containing functional groups present in 
GO (of which the GO must partly comprise) do not form superlattice type ordered arrays [24]. (Figure 2)

\section{Electrochemical activity of GO}

To confirm surface modification, electrochemical behavior was analyzed in Zobell's solution ( $3 \mathrm{mM} \mathrm{K} \mathrm{K}_{3} \mathrm{Fe}(\mathrm{CN})$ and $\left.0.1 \mathrm{M} \mathrm{KCl}\right)$, using Cyclic Voltammetry (CV) for both bare ITO and GO/ITO electrodes. As shown in Figure 3A, it is observed that for GO/ITO electrode, the anodic and cathodic peak current decreases slightly as compared to bare ITO surface. In addition, the peak potential separation $\left(\Delta \mathrm{E}_{\mathrm{p}}\right)$ between anodic and cathodic peaks increased from $0.215 \mathrm{~V}$ to $0.288 \mathrm{~V}$ for ITO and GO/ITO, respectively, confirming successful surface modification by GO. To further assess the electrochemical behavior of GO/ITO, $\mathrm{CV}$ studies have been carried out at different scan rates in Zobell's solution. Figure 3B, the CV of GO/ITO electrode in Zobell's solution as a function of scan rate $\left(0.02-0.16 \mathrm{Vs}^{-1}\right)$ exhibits significant increase in redox peak current $\left(\mathrm{I}_{\mathrm{p}}\right)$ with the increase in scan rate. In addition to this, $\Delta \mathrm{E}$ ranging from $0.2 \mathrm{~V}$ to $0.344 \mathrm{~V}$ increases with increase in scan rate indicating the quasi-reversible kinetics of the GO/ITO electrode. The linear relationship in peak current $\mathrm{I}_{\mathrm{p}}$ (both $\mathrm{I}_{\mathrm{p}}$ and $\mathrm{I}_{\mathrm{p}}$ ) versus square root of scan rate $\left(\mathrm{v}^{1 / 2}\right)$, shown in Figure $3 \mathrm{C}$ reveals that the electrochemical reaction at the surface of GO/ITO electrode is a diffusion-controlled process $[25,26]$. The regression coefficient $\left(R^{2}\right)$ for linear fit of $\mathrm{I}_{\mathrm{pa}}$ and $\mathrm{I}_{\mathrm{pc}}$ were calculated to be 0.9660 and 0.9734 , respectively.
The ratio of $\mathrm{I}_{\mathrm{pc}} / \mathrm{I}_{\mathrm{pa}}=1.028$ (at $20 \mathrm{mVs}^{-1}$ ), which is less than 1.27 is ruling out the possibility of an irreversible electron transfer process $[27,28]$. The value of $I_{p c} / I_{p a}=1.028$ nearly equals to 1 entails that the electron transfer process is quasi-reversible that is approaching towards reversible kinetics. As an approximate case, considering the process to be a reversible at low scan rates, diffusion coefficient ' $D$ ' has been calculated as $3.3376 \times 10^{-5} \mathrm{~cm}^{2} \mathrm{~s}^{-1}$, using Randal-Sevcik equation [29] (1) for planar electrodes.

$$
\mathrm{I}_{\mathrm{p}}=\left(2.69 \times 10^{5}\right) \mathrm{n}^{3 / 2} \mathrm{AD}^{1 / 2} \mathrm{Cv}^{1 / 2}
$$

Where $\mathrm{I}_{\mathrm{p}}$ is the peak current, $\mathrm{v}$ is scan rate in $\mathrm{Vs}^{-1}, \mathrm{~A}$ is area of film in $\mathrm{cm}^{2}\left(0.48 \mathrm{~cm}^{2}\right.$ in our case), $\mathrm{C}$ is the bulk concentration (here $3 \mathrm{mM}$ for $\mathrm{FeCN}_{6}^{-3}$ ), ' $\mathrm{n}$ ' is number of electron transfer per molecule in oxidation process (here $\mathrm{n}=1$ ). The thickness of the film has been found as $15 \mathrm{~nm}$ using Dektak-150 thickness profiler (Veeco Pvt Ltd.) (Figure 3).

Figure 3D shows the plot for dimensionless kinetic parameter $(\Psi)$ and $\Delta \mathrm{E}_{\mathrm{p}}$ for $\mathrm{GO}$ electrode. Following Nicholson's working curve [30], the values of dimensionless kinetic parameter $\Psi$ have been calculated from $\Delta \mathrm{E}_{\mathrm{p}}$ and found to be directly proportional to the reciprocal of the square root of scan rate $\left(\mathrm{v}^{-1 / 2}\right)$. Using linear fit curve, the value of standard heterogeneous rate constant $\left(\mathrm{k}^{0}\right)$ has been determined as $1.4 \times 10^{-3} \mathrm{cms}^{-1}$ following equation (2):

$$
\Psi=\mathrm{k}^{0}[\mathrm{RT} /(\mathrm{nFD})]^{1 / 2} \mathrm{v}^{-1 / 2}
$$
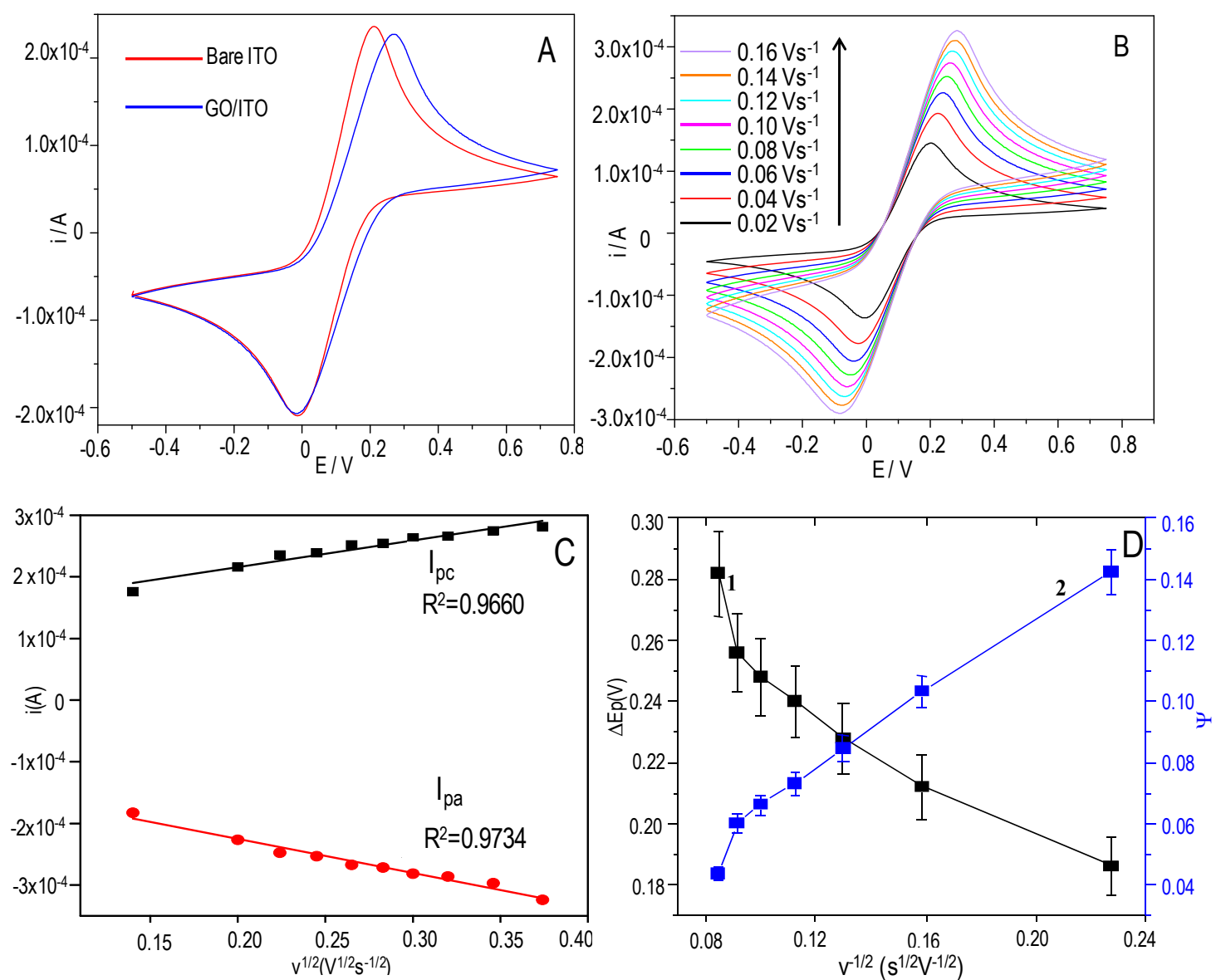

Figure 3: (A) Cyclic voltammertic (CV) studies of bare ITO and GO/ITO at $0.05 \mathrm{Vs}^{-1}$ in Zobell's solution at $25^{\circ} \mathrm{C}$; (B) $\mathrm{CV}$ of GO/ITO for various scan rates $\left(0.02-0.16 \mathrm{Vs}^{-1}\right)$ in Zobell's solution at $25^{\circ} \mathrm{C} ;(\mathrm{C})$ Plot of peak current $\left(\mathrm{I}_{\mathrm{pa}}\right.$ and I $\mathrm{I}_{\mathrm{p}}$ ) vs square root of scan rate $\left(\mathrm{v}^{1 / 2}\right)$; (D) Plot of $\Delta \mathrm{E}_{\mathrm{p}}$ and Nicholson's kinetic parameter $(\Psi)$ versus reciprocal of square root of scan rate $\left(\mathrm{v}^{-1 / 2}\right)$. 
The obtained value of $\mathrm{k}^{0}$ falls in the range of quasi-reversible electron transfer process $\left(5 \times 10^{-5} \mathrm{~cm} \mathrm{~s}^{-1} \geq \mathrm{k}^{0} \geq 2 \times 10^{-2} \mathrm{~cm} \mathrm{~s}^{-1}\right)$ in agreement with literature [31]. The redox process for GO is significantly contributing towards improved electron transfer owing to its inherent electron transfer property and rise in values of $\mathrm{k}^{0}$ and diffusion coefficient (D) provide important insight towards this behavior. As compared to literature, value of diffusion coefficient of GO in Zobell's solution has been improved by one order of magnitude compared to CVD-GO/ graphite oxide [32]. Similarly, improvement in heterogeneous electron transfer rate $\left(\mathrm{k}^{0}\right)$ for $\mathrm{GO}$ clearly insinuates that this favorable rise (both $\mathrm{D} \& \mathrm{k}^{0}$ ) for $\mathrm{GO} / \mathrm{ITO}$ electrode is ascribed to the uniformly distributed $\mathrm{GO}$ nano-sheets and their polycrystalline structure. The results indicate that GO films exhibits better electrochemical properties to achieve a stable and robust electrochemical biosensing device. Further, it is introspected that oxygen-containing groups in $\mathrm{GO}$ are contributing hydrophilicity and rapid electron transfer where aromatic regions provides active sites for $\pi-\pi$ supra-molecular interactions [33].

\section{Fabrication and characterization of $\mathrm{GO} / \mathrm{ITO}$ and $\mathrm{Ab} / \mathrm{GO} /$ ITO immunoelectrodes}

Infrared absorbance spectra of graphene oxide and antibody immobilized graphene oxide films in transmission mode are shown in Figure 4A. The FTIR spectrum reveals the characteristic peaks of graphene oxide (curve i) showing the presence of hydroxyl (C-OH, $\left.3050-3800 \mathrm{~cm}^{-1}\right)$ at $3420 \mathrm{~cm}^{-1}$, carboxyl $\left(\mathrm{COOH}, 1650-1750 \mathrm{~cm}^{-1}\right)$ at $1747 \mathrm{~cm}^{-1}$, ketonic species $\left(\mathrm{C}=\mathrm{O}, 1600-1650 \mathrm{~cm}^{-1}\right)$ at $1636 \mathrm{~cm}^{-1}$ and asymmetric vibrational stretching of $\mathrm{sp}^{2}$ hybridized $(\mathrm{C}=\mathrm{C}, 1500-1600$ $\mathrm{cm}^{-1}$ ) at $1545 \mathrm{~cm}^{-1}$. Furthermore, the presence of some overlapped regions such as $\alpha$-region (lactols, peroxides, dioxolanes, hydroxyls, epoxides, $900-1100 \mathrm{~cm}^{-1}$ ) at $1020 \mathrm{~cm}^{-1}$ and $\gamma$-region (ethers, epoxide, peroxide, ketones, benzoquinonoes, $1280-1500 \mathrm{~cm}^{-1}$ ) at $1445 \mathrm{~cm}^{-1}$ are attributed to oxidized graphene sheets i.e. GO [34]. It is observed that the intensities of IR peaks get suppressed after immobilization of antibodies onto GO/ITO (curve ii). The emergence of additional strong peak at $1560 \mathrm{~cm}^{-1}$ related to characteristic N-H bending vibrations (1480-1575 $\mathrm{cm}^{-1}$ ) of amide II due to the presence of anti-hTERT (Ab) confirms the binding of antibodies onto GO/ITO electrode [35] (Figure $4)$.

Figure 4B-4D depicts the SEM images (Zeiss EVO MA10 Scanning electron microscope) of GO/ITO, Ab/GO/ITO and hTERT/Ab/GO/ ITO surface, respectively at $20 \mathrm{Kx}$, along with schematic illuminating stepwise morphological changes with fabrication steps. Figure $4 \mathrm{~B}$ shows a wrinkled/pleated sheet of GO on ITO coated glass slide. Further, GO/ ITO electrode functionalized with $\mathrm{Ab}$ contains uniformly distributed globules onto the surface of GO (Figure 4C), confirming the successful immobilization of $\mathrm{Ab}$. Ab/GO/ITO immunoelectrode was exposed to hTERT (specific antigen) to affirm the binding of antigen to the antibodies immobilized on the surface of immunoelectrode. Change in morphology and presence of lighter colored regions can be assigned to binding of antigen (hTERT) onto Ab/GO/ITO surface (Figure 4D).

\section{Electrochemical characterization and response studies of $\mathrm{Ab} /$ GO/ITO immunoelectrode}

The CV and DPV studies of immuno-electrode were carried out to identify the specific and non-specific antigen interaction. Figure $5 \mathrm{~A}$ shows the $\mathrm{CV}$ curves of GO/ITO, Ab/GO/ITO and hTERT/Ab/ $\mathrm{GO} / \mathrm{ITO}$ at scan rate of $50 \mathrm{mV} \mathrm{s}^{-1}$. It is found that after the covalent immobilization of $\mathrm{Ab}$ on to $\mathrm{GO} / \mathrm{ITO}$ electrode, peak current decreases significantly from $2.213 \times 10^{-4} \mathrm{~A}$ to $1.711 \times 10^{-4} \mathrm{~A}$ for $\mathrm{Ab} / \mathrm{GO} / \mathrm{ITO}$ surface. Subsequent, observed decrease in peak current to $1.551 \times 10^{-4} \mathrm{~A}$ due to
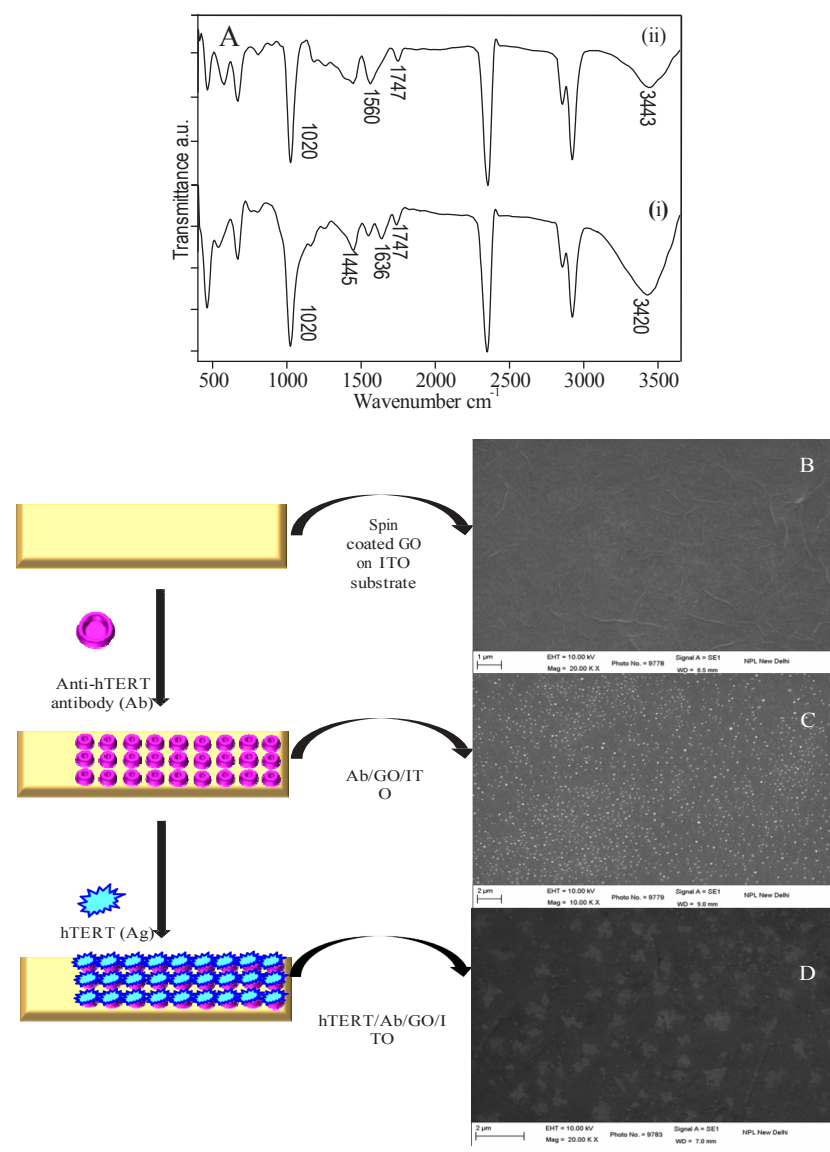

Figure 4: (A) FTIR spectrum of GO (curve 1) and Ab/GO/ITO (curve 2) indicating the presence of functional groups; (B-D) SEM images of GO/ITO, Ab/GO/ITO and hTERT/Ab/GO/ITO immunoelectrode along with schematic representation of respective surface modifications on the left side.

binding of hTERT onto surface of Ab/GO/ITO immunoelectrode can be attributed to surface coverage by the protein that masks the electron transfer process [36]. These results are in agreement with the SEM studies revealing successful fabrication of immunoelectrode.

$\mathrm{DPV}$ response studies of $\mathrm{Ab} / \mathrm{GO} / \mathrm{ITO}$ immunoelectrode carried out for various concentrations ( $10 \mathrm{ag} \mathrm{mL}^{-1}-50 \mathrm{ng} \mathrm{mL} \mathrm{L}^{-1}$ ) of hTERT with exposure time of $30 \mathrm{~s}$ at $25^{\circ} \mathrm{C}$ are shown in Figure 5B. It is observed that peak current decreases when hTERT binds to the surface of $\mathrm{Ab} /$ GO/ITO immunoelectrode. These observations are in tune with the SEM and CV studies, reconfirming the antigen-antibody interaction onto the immunosensor surface. It is further noted here that the peak current continue to decrease with the increase in the antigen (hTERT) concentration. DPV studies reveal that $50 \mathrm{ng} \mathrm{mL}^{-1} \mathrm{hTERT}$ is the surface saturation concentration for $\mathrm{Ab} / \mathrm{GO} / \mathrm{ITO}$ immunoelectrode and beyond this concentration no further decrease in peak current is observed. On the other end, lowest concentration of hTERT capable of bringing decrease in DPV peak height is $10 \mathrm{ag} \mathrm{mL}^{-1}$. Besides this, as shown in Figure 5C, the linear regression equation: $\mathrm{I}_{\mathrm{pa}}(\mu \mathrm{A})=14.6986-1.2912 \log$ $\mathrm{C}_{\text {hTERT }}\left(\mathrm{ag} \mathrm{mL}-1\right.$ ) with $\mathrm{R}^{2}=0.99318$ is fitting in range of $100 \mathrm{fg} \mathrm{mL}^{-1}$ to 50 ng mL ${ }^{-1}$ hTERT. The fabricated Ab/GO/ITO immunoelectrode possess remarkable response characteristics showing $10^{6}$ times improved detection limit with $30 \mathrm{~s}$ antigen exposure time [37].

Figure 5D shows DPV response curves of $\mathrm{Ab} / \mathrm{GO} / \mathrm{ITO}$ immunoelectrode exposed to non-specific cancer antigens (CD-59, 

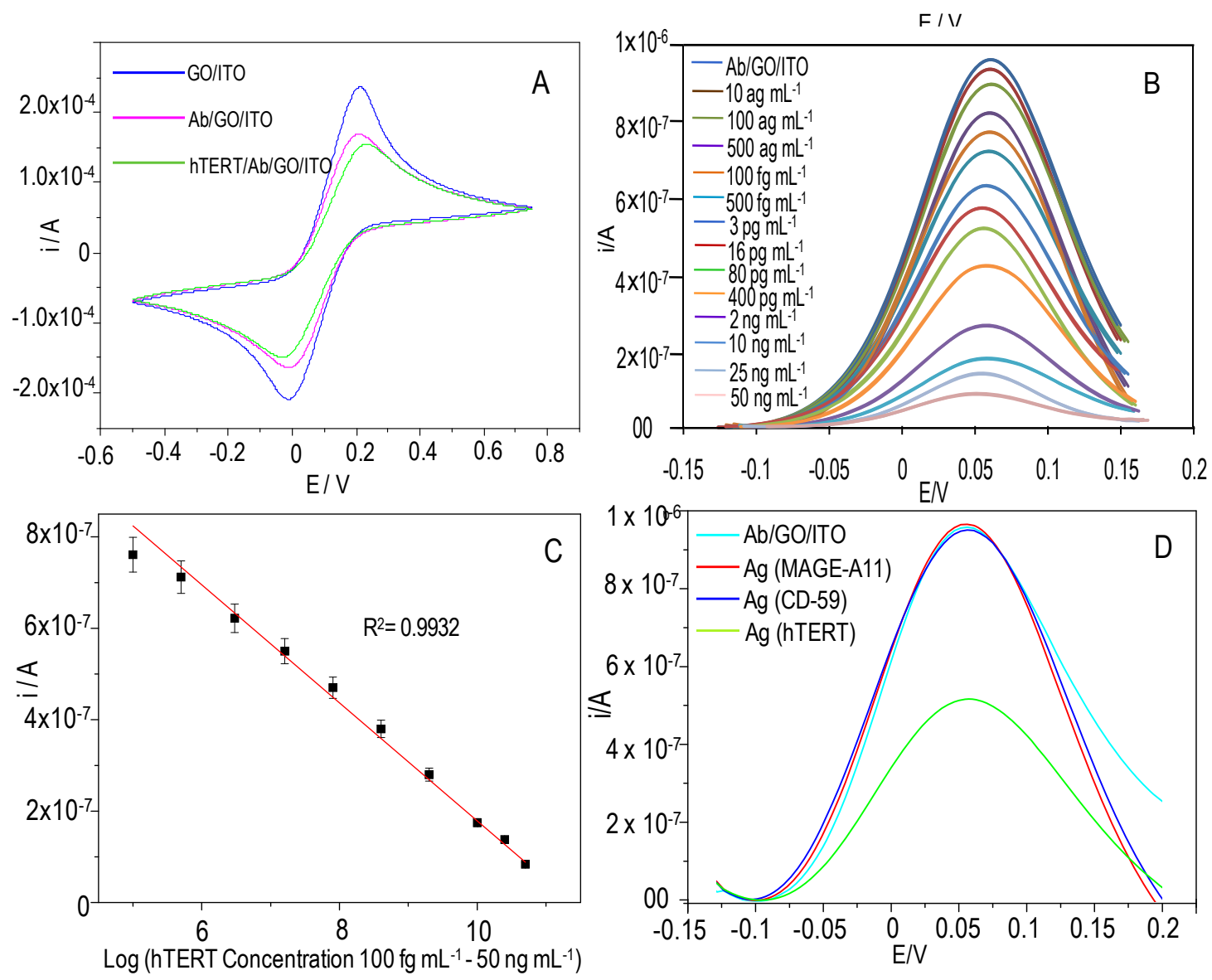

Figure 5: (A) CV studies of GO/ITO, Ab/GO/ITO and hTERT/Ab/GO/ITO in zobell's solution at $0.05 \mathrm{Vs}{ }^{-1}$; (B,D) DPV response studies of Ab/GO/ITO immunoelectrode in $0.05 \mathrm{mM} \mathrm{K} \mathrm{Fe}(\mathrm{CN})$ contained in $5 \mathrm{mM}$ PBS, pH 7.4 at pulse amplitude $0.03 \mathrm{~V}$ and pulse width $0.05 \mathrm{~s}$ : (B) DPV for various hTERT concentration (10 ag mL-1-50 $\mathrm{ng} \mathrm{mL}^{-1}$ ); (C) Calibration of the immunosensor for hTERT determination; (D) DPV for specific (hTERT) and non-specific antigen (CD-59, MAGE-A11).

MAGE-A11) $10 \mathrm{pg} \mathrm{mL}^{-1}$ each, in $5 \mathrm{mM}$ PBS containing $0.05 \mathrm{mM}$ $\mathrm{K}_{3} \mathrm{Fe}(\mathrm{CN})_{6}$. $\mathrm{Ab} / \mathrm{GO} / \mathrm{ITO}$ immuno-electrode exhibited remarkable specificity, as there was no appreciable decrease in peak current corresponds to non-specific antigens CD-59 and MAGE-11. hTERT/ $\mathrm{Ab} / \mathrm{GO} / \mathrm{ITO}$ immuno-electrodes were also examined to evaluate the reusability of the immunosensor, using $30 \mathrm{mM} \mathrm{NaOH}$ solution $(60 \mathrm{~s}$ exposure time) to break the antibody-antigen linkage. Interestingly, it was found that regenerated $\mathrm{Ab} / \mathrm{GO} / \mathrm{ITO}$ immunoelectrode showed $\mathrm{DPV}$ response similar to the native $\mathrm{Ab} / \mathrm{GO} / \mathrm{ITO}$. The fabricated immuno-electrode retains $100 \%$ signal after four subsequent regeneration cycles and showed decrease in the signal to $~ 92.5 \%$ after $5^{\text {th }}$ regeneration cycle having relative Standard Deviation (SD) of $5.6 \%$. Besides this, Ab/GO/ITO immunoelectrode has been found to retain $100 \%$ DPV response signal after 4 weeks of its fabrication when stored in desiccated condition at $4^{\circ} \mathrm{C}$. (Figure 5)

\section{Application of the immunoelectrode in hTERT spiked sputum samples}

To investigate the implications of fabricated $\mathrm{Ab} / \mathrm{GO} / \mathrm{ITO}$ immunoelectrode for real biological samples, experiments have been performed using spiked sputum samples. Sputum of normal healthy person was collected and centrifuge two times at $3000 \mathrm{rpm}$ for 15 minutes. Clear supernatant was further diluted in PBS (1:4) and used to investigate the response studies of Ab/GO/ITO immunoelectrode at $25^{\circ} \mathrm{C}$. It is observed that DPV response slightly shifts to higher potential (Figure 6A), and is ascribed to the binding of certain salts and other non-specific interferents to the immunoelectrode surface. It can be seen that $\mathrm{Ab} / \mathrm{GO} / \mathrm{ITO}$ immunoelectrode is able to detect upto $100 \mathrm{fg} \mathrm{mL}^{-1}$ of hTERT in spiked sputum and peak current continued to decrease till $10 \mathrm{ng} \mathrm{mL}^{-1}$ of hTERT. The linear regression equation: $\mathrm{I}_{\mathrm{pa}}(\mu \mathrm{A})=8.83931$ $1.10668 \log \mathrm{C}_{\text {hTERT }}\left(\mathrm{fg} \mathrm{mL}^{-1}\right)$ with $\mathrm{R}^{2}=0.96173$ is fitting in range of 100 fg $\mathrm{mL}^{-1}$ to $10 \mathrm{ng} \mathrm{mL}^{-1}$ for hTERT in spiked sputum (Figure $6 \mathrm{~B}$ ). These results indicate that fabricated electrode exhibited a good analytical performance with spiked sputum samples and has implications for its application to investigate other cancer biomarkers in real biological fluids.

Furthermore, the analytical performance of the fabricated immunoelectrode has been compared with that of various recent immunosensors based on existing literature [38-49], as shown in Table 1. The present immunoelectrode displayed a good performance with considerable specificity and low detection of analytic concentration. The novelties exhibited by the designed immunosensor are attributed to the multifunctional nature and better physicochemical properties of graphene oxide. 

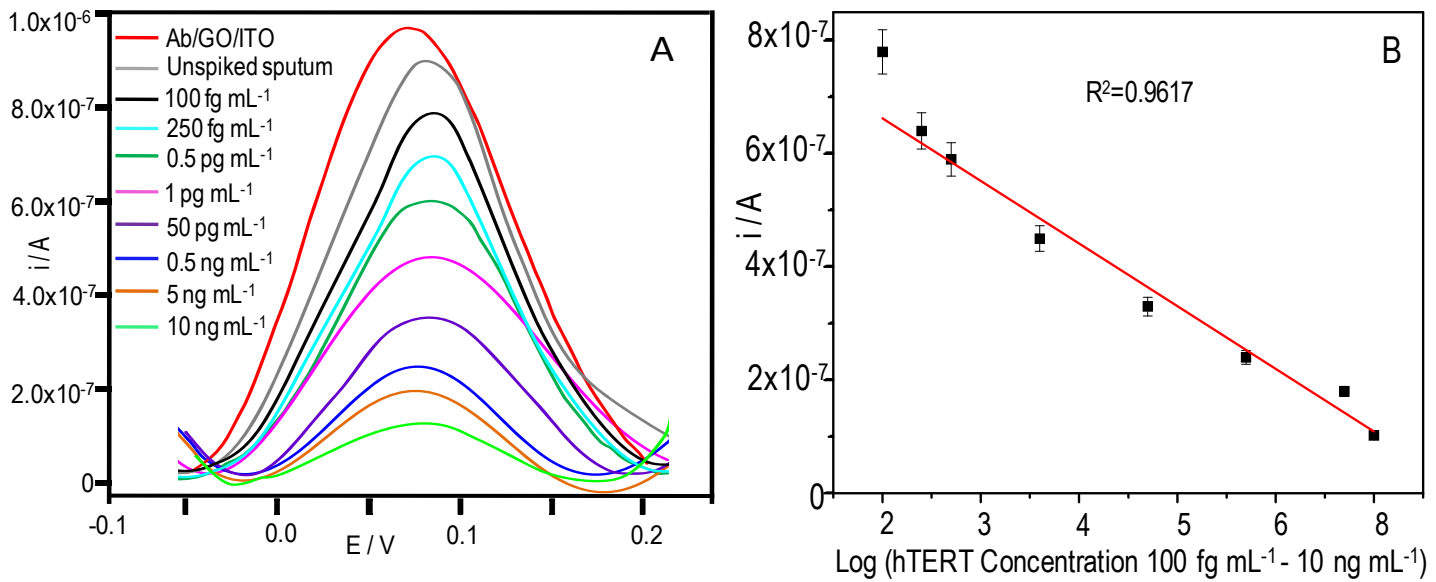

Figure 6: (A) DPV response studies of $\mathrm{Ab} / \mathrm{GO} / \mathrm{ITO}$ immunoelectrode in $0.05 \mathrm{mM} \mathrm{K}_{3} \mathrm{Fe}(\mathrm{CN})_{6}$ contained in $5 \mathrm{mM} \mathrm{PBS}$, pH 7.4 at pulse amplitude $0.03 \mathrm{~V}$ and pulse width $0.05 \mathrm{~s}$ for various hTERT concentration (100 $\mathrm{fg} \mathrm{mL}^{-1}-10 \mathrm{ng} \mathrm{mL}^{-1}$ ) spiked in sputum; (B) Calibration of the immunosensor for hTERT determination in spiked sputum.

\section{Stability, reproducibility and reusability studies of $\mathrm{Ab} / \mathrm{GO} /$ ITO immunoelectrode}

The stability of the Ab/GO/ITO immunoelectrodes has been evaluated for over a period of one month. The immunoelectrodes were stored at $4^{\circ} \mathrm{C}$ after fabrication. Stability of the designed electrodes was studied by incubating them with $50 \mathrm{pg} \mathrm{ml}^{-1}$ of hTERT and DPV was performed before and after incubation with hTERT. The activity of the immunosensors was evaluated and found no loss of signal upto $20^{\text {th }}$ day after incubation. After that the signal was decreased slowly. Therefore, the designed electrode is suitable for hTERT analysis up to 20 days. To evaluate the reproducibility of the immunosensors, a series of five immunosensors were prepared for detecting $50 \mathrm{pg} \mathrm{mL}^{-1}$ hTERT. The Relative Standard Deviation (RSD) of the measurements for the five electrodes was $5.3 \%$, suggesting the precision and reproducibility of the immunosensor was quite good. In an effort to evaluate the reusability of the immunosensor, $30 \mathrm{mM} \mathrm{NaOH}$ solution was used to break the antibody-antigen linkage. After detecting $2 \mathrm{ng} \mathrm{mL}^{-1}$ of hTERT, the immunosensor was dipped into the $\mathrm{NaOH}$ solution for $60 \mathrm{~s}$, and used to detect hTERT again. The immunosensor retained $92.5 \%$ of the initial value after 5 regeneration cycles and a RSD of $5.6 \%$ was obtained. The good regeneration ability demonstrated by the immunosensor may be attributed to the good stability of the antibody on the electrode surface through covalent binding.

\section{Conclusion}

In conclusion, Graphene Oxide prepared from graphite using modified Hummer's method is successfully used to deposit thin films of GO onto ITO coated glass substrate. An ultrasensitive label free electrochemical immunosensor has been developed by covalent immobilization of anti-hTERT antibody onto GO/ITO. The results indicate that the $\mathrm{Ab} / \mathrm{GO} / \mathrm{ITO}$ immunoelectrode can effectively sense hTERT at low level of concentration upto $10 \mathrm{ag} \mathrm{mL}^{-1}$ with linear detection range of $100 \mathrm{fg} \mathrm{mL}^{-1}-50 \mathrm{ng} \mathrm{mL}^{-1}$ hTERT. The Ab/GO/ITO electrode showed in the detection of hTERT in spiked sputum samples in the dynamic range of $100 \mathrm{fg} \mathrm{mL}^{-1}-10 \mathrm{ng} \mathrm{mL}^{-1}$ hTERT, suggesting its potential for real biological fluid samples. Besides this, the immunoelectrode retained its activity after multiple uses. The excellent performance of the immunosensor is ascribed to graphene oxide that provides favorable microenvironment for protein immobilization and promotes direct electron transfer at the electrode surface and larger surface area. The ease of fabrication using low-cost process, the graphene oxide based immunosensor promises for cost effective commercial device for early detection of lung cancer. Further, the compatibility of GO to integrate with MEMS technology could pave the way for the development of miniaturized immunosensors towards point-of -care diagnostics.

\section{Acknowledgment}

We are grateful to Prof. Sopory, Vice Chancellor, JNU; Prof. Madhubala, Director, AIRF, JNU and Prof. Budhani, Director, NPL, New Delhi, India for showing interest in this work. MC is thankful to DBT for providing JRF. Veeresh Kumar is thankful to UGC for providing SRF. Financial support received under the DBTsponsored project IYBA-2008 (BT/B1/12/045/2008) and RGYI-2009 (BT/PR13127) $\mathrm{GBD} / 27 / 195 / 2009$ ) is sincerely acknowledged.

\section{References}

1. Cavalli $F$ (2006) Cancer in the developing world: Can we avoid the disaster? Nat Clin Pract Oncol 3: 582-583.

2. Cancer Incidence and Mortality Worldwide (2010) IARC Cancer Base No.10. International Agency for Research on Cancer Lyon, France.

3. Sone S, Takashima S, Li F, Yang Z, Honda T, et al. (1998) Mass screening for lung cancer with mobile spiral computed tomography scanner. Lancet 351 : 1242-1245.

4. Arya SK, Bhansali S (2011) Lung cancer and its early detection using biomarkerbased biosensors. Chem Rev 111: 6783-6809.

5. Bensalah K, Lotan Y, Karam JA, Shariat SF (2008) New circulating biomarkers for prostate cancer. Prostate Cancer Prostatic Dis 11: 112-120.

6. Oikawa S, Inuzuka C, Kuroki M, Arakawa F, Matsuoka Y, et al. (1991) A specific heterotypic cell adhesion activity between members of carcinoembryonic antigen family, W272 and NCA, is mediated by N-domains. J Biol Chem 266: 7995-8001.

7. Hanahan D, Weinberg RA (2000) The Hallmarks of Cancer. Cell 100: 57-70.

8. Weinrich SL, Pruzan R, Ma L, Ouellette M, Tesmer VM, et al. (1997) Reconstitution of human telomerase with the template RNA component hTR and the catalytic protein subunit hTRT. Nat Genet 17: 498-502.

9. Kim NW (1997) Clinical implications of telomerase in cancer. Eur J Cancer 33 781-786. 
Citation: Choudhary M, Kumar V, Singh A, Singh MP, Kaur S, et al. (2013) Graphene Oxide based Label Free Ultrasensitive Immunosensor for Lung Cancer Biomarker, hTERT. J Biosens Bioelectron 4: 143. doi: 10.4172/2155-6210.1000143

10. Fernández-Marcelo T, Morán A, de Juan C, Pascua I, Head J et al. (2012) Differential expression of senescence and cell death factors in non-small cell lung and colorectal tumors showing telomere attrition. Oncology 82: 153-164.

11. Sozzi G, Conte D, Leon M, Ciricione R, Roz L, et al. (2003) Quantification of free circulating DNA as a diagnostic marker in lung cancer. J Clin Oncol 21: 3902-3908.

12. Aebersold R, Mann M (2003) Mass spectrometry-based proteomics. Nature 422: 198-207.

13. Zhang B, Zhang X, Yan HH, Xu SJ, Tang DH, et al. (2007) A novel multiarray immunoassay device for tumor markers based on insert-plug model of piezoelectric immunosensor. Biosens Bioelectron 23: 19-25

14. Zhiai X, Chen X, Dong S (2006) Electrochemical biosensors based on advanced bio immobilization matrices. TrAC 25: 899-908.

15. Sotiropoulou S, Gavalas V, Vamvakaki V, Chaniotakis NA (2003) Novel carbon materials in biosensor systems. Biosens Bioelectron 18: 211-215.

16. Rao CN, Sood AK, Subrahmanyam KS, Govindaraj A (2009) Graphene: The new two-dimensional nanomaterial. Angew Chem Int Ed Engl 48: 7752-7777.

17. Novoselov KS, Fal'ko VI, Colombo L, Gellert PR, Schwab MG, et al. (2012) A roadmap for graphene. Nature 490: 192-200.

18. Stoller MD, Park S, Zhu Y, An J, Ruoff RS (2008) Graphene-based ultracapacitors. Nano Lett 8: 3498-3502.

19. Wang Y, Li Y, Tang L, Lu J, Li J (2009) Application of graphene-modified electrode for selective detection of dopamine. Electrochem Commun 11: 889892.

20. Tang L, Wang Y, Li Y, Feng H, Lu J, et al. (2009) Preparation, structure, and electrochemical properties of reduced graphene sheet films. Adv Funct Mate 19:2782-2789.

21. Pumera M, Ambrosi A, Bonanni A, Khim Chng EL, Poh HL (2010) Graphene for electrochemical sensing and biosensing. TrAC 29: 954-965.

22. Li D, Müller MB, Gilje S, Kaner RB, Wallace GG (2008) Processable aqueous dispersions of graphene nanosheets. Nat Nanotechnol 3: 101-105.

23. Cote LJ, Kim F, Huang J (2009) Langmuir-Blodgett assembly of graphite oxide single layers. J Am Chem Soc 131: 1043-1049.

24. Warner JH, Rümmeli MH, Gemming T, Büchner B, Briggs GA (2009) Direct imaging of rotational stacking faults in few layer graphene. Nano Lett 9: 102-

25. Paul HJ, Leddy J (1995) Direct determination of the transfer coefficient from cyclic voltammetry: Isopoints as diagnostics. Anal Chem 67: 1961-1968.

26. Dreyer DR, Park S, Bielawski CW, Ruoff RS (2010) The chemistry of graphene oxide. Chem Soc Rev 39: 228-240.

27. Zanello P (2003) Inorganic electrochemistry: Theory, practice and application Royal Soc Chem 630.

28. Wang J (2006) Analytical electrochemistry. (3rd Edn), Wiley-Vch, USA 272.

29. Randles JEB (1948) A cathode ray polarograph. II The current voltage curves. Trans Faraday Soc 44: 327-338.

30. Nicholson RS (1965) Theory and application of cyclic voltammetry for measurements of electrode reaction kinetics. Anal Chem 37: 1351-1355.

31. Li X, Wang X, Zhang L, Lee S, Dai H (2008) Chemically derived, ultrasmooth graphene nanoribbon semiconductors. Science 319: 1229-1232.

32. Chua CK, Pumera M (2012) Reduction of graphene oxide with substituted borohydrides. J Mater Chem A 1: 1892-1898.

33. Sharma P, Bhalla V, Dravid V, Shekhawat G, Jinsong-Wu, et al. (2012) Enhancing electrochemical detection on graphene oxide-CNT nanostructured electrodes using magneto-nanobioprobes. Sci Rep 2: 877.

34. Acik M, Lee G, Mattevi C, Chhowalla M, Cho K, et al. (2010) Unusual infraredabsorption mechanism in thermally reduced graphene oxide. Nat Mater 9: 840845
35. Krimm S, Bandekar J (1986) Vibrational spectroscopy and conformation of peptides, polypeptides, and proteins. Adv Protein Chem 38: 181-364.

36. Han J, Zhuo Y, Chai YQ, Mao L, Yuan YL, et al. (2011) Highly conducting gold nanoparticles-graphene nanohybrid films for ultrasensitive detection of carcinoembryonic antigen. Talanta 85:130-135.

37. Sharma P, Tuteja SK, Bhalla V, Shekhawat G, Dravid VP, et al. (2013) Biofunctionalized graphene-graphene oxide nanocomposite based electrochemical immunosensing. Biosens Bioelectron 39: 99-105.

38. Yu T, Cheng W, Li Q, Luo C, Yan L, et al. (2012) Electrochemical immunosenso for competitive detection of neuron specific enolase using functional carbon nanotubes and gold nanoprobe. Talanta 93: 433-438.

39. Ge S, Jiao X, Chen D (2012) Ultrasensitive electrochemical immunosenso for CA15-3 using thionine-nanoporous gold-graphene as a platform and horseradish peroxidase-encapsulated liposomes as signal amplification. Analyst 137: 4440-4447.

40. Ojeda I, López-Montero J, Moreno-Guzmán M, Janegitz BC, GonzálezCortés A, et al. (2012) Electrochemical immunosensor for rapid and sensitive determination of estradiol. Anal Chim Acta 743: 117-124.

41. Li Q, Li N, Tissier PL, Grattan DR, Kerman K (2012) Miniaturized electrochemica immunosensor for label-free detection of growth hormone. Electroanalysis 24 1272-1276.

42. Kim A, Ah CS, Park CW, Yang JH, Kim T, et al. (2010) Direct label-free electrical immunodetection in human serum using a flow-through- apparatus approach with integrated field-effect transistors. Biosens Bioelectron 25: 1767-1773.

43. Liu K, Zhang JJ, Wang C, Zhu JJ (2011) Graphene-assisted dual amplification strategy for the fabrication of sensitive amperometric immunosensor. Biosens Bioelectron 26: 3627-3632.

44. Su B, Tang J, Huang J, Yang H, Qiu B, et al. (2010) Graphene and nanogoldfunctionalized immunosensing interface with enhanced sensitivity for onestep electrochemical immunoassay of alpha-fetoprotein in human serum. Electroanal. 22: 2720-2728.

45. Han J, Zhuo Y, Chai YQ, Mao L, Yuan YL, et al. (2011) Highly conducting gold nanoparticles-graphene nanohybrid films for ultrasensitive detection of carcinoembryonic antigen. Talanta 85: 130-135.

46. Chebil S, Hafaiedh I, Dorizon HS, Renault JN, Errachid A, et al. (2010) Electrochemical detection of D-dimer as deep vein thrombosis marker using single-chain D-dimer antibody immobilized on functionalized polypyrrole. Biosens Bioelectron 26: 736-742.

47. Shan C, Yang H, Han D, Zhang Q, Ivaska A, et al. (2010) Graphene/AuNPs/ chitosan nanocomposites film for glucose biosensing. Biosens Bioelectron 25: 1070-1074.

48. Kang X, Wang J, Wu H, Aksay IA, Liu J, et al. (2009) Glucose oxidasegraphene-chitosan modified electrode for direct electrochemistry and glucose sensing. Biosens Bioelectron 25: 901-905.

49. Yang M, Gong S (2010) Immunosensor for the detection of cancer biomarker based on percolated graphene thin film. Chem Commun (Camb) 46: 5796 5798. 